\title{
Applicated Pricing Strategies in Jordanian Medicine Scoter and There Effects On Customer Satisfaction (View Point Of Mangers)
}

\author{
Dr. Mohmud Agel Abo-Dalbouh \\ Associate Professor of Marketing \\ Irbid University
}

\begin{abstract}
The aims of study to know the "applicated pricing strategies in Jordanian medicine sector and there effects on customer satisfaction "according to the perspective of the market medicine, pricing, satisfaction and its importance, it focus on a problems faced by prices, customer income, quality, performance of medicine sector. The study showed pricing strategies and there obstacles to achieve customer satisfaction and how to choose the suitable strategy for pricing the medicines and for test the relation between price and satisfaction. The medicine sector face obstacles' as working capital, cost, patent regulations', laws, customer satisfaction, a suitabl strategy and policies to achieve medicine sector objectives, there are three dimensions' for independent factors (skimming strategy, penetration strategy, expected value strategy) and customer satisfaction. The study population is consist of all companies in medicine sector (106) company in survey and analytical study, view point of managers, concluded that rapid skimming pricing strategy depend on the importance of medicine product but low skimming pricing strategy depend on promotion effort, rapid penetration pricing strategy depend on low price as an entrance for the medicine market. The study showed that: The prices were very high, the market share is low, the customer satisfaction is low the sector, improvement is costly. The study recommended the Jordanian medicine sector must be combining to meet low customer satisfaction by focus on quality, low prices, increase market share, improvement the sector, decrease the cost, reinforce the competition abilities.
\end{abstract}

Keywords: medicine sector, customer satisfaction, penetration, skimming strategy, prices.

\section{The Study Problem}

The Jordanian medicine sector face many obstacles' in the light of communications revolution, opening market's competition, low level awareness of

A: Styles of reducing the cost.

B: Knowledge of patent, innovations regulations.

C: New method of pricing.

D: How to focus on suitable pricing strategy to achieve the customer satisfaction.

\section{METHODOLOGY OF THE STUDY}

The researcher adopted the descriptive analysis approach to study the Jordanian medicine sector and apply the study on all companies (106) company, but the response for questionnaire are (81) company.

\section{Data Collection Method}

Data were collected by two ways: 
Primary data: by questionnaire is adopted, judgments, distributed to the medicine sector managers to find out the extent of there satisfaction about applied pricing strategies and there effect on customer satisfaction.

Secondary data: adoption of references, periodicals, websites, researches.

Questionnaire was sent to a number of professors professionals for arbitration.

\section{Theoretical Framework}

The marketing activities need processes of continues development of harmony with the forces of the total and partial dynamic environment, interaction with rapid changes of needs, desires, preferences of customers, and for as to increase the ability of firms in Jordanian medicine sector.

The marketing research, consumer behaviors, analysis the sales, and marketing of opportunities have become necessity preceding the planning of marketing mix process or pricing process or applied strategy and developing pricing strategy for marketing product and achieving full goals of firms in medicine sector by managers view point.

\section{Previous Studies}

Ahmed Bader Al_dean (2014) "the future medicine production in Egypt. "Egypt. The study aimed to draw new policies for future production, customer needs and wants, quality, assurance, improvement the medicine, promotion styles focus on customer satisfaction. The study explain the policies and strategies which applied in medicine sector, leak of protection lows, shortage of medicine for many citizens slices, leak of research, leak of government support, low of development in technology part.

The study recommended by: react the pricing policies, cost, researches, laws, government support, promotion policy, spread the medicine coverage.

Hawary, M. Ismail (2010) "effect of information technology for achieving competitive advantage" Jordan.

The study aimed to explore the application of technology y on competitive advantage, the study applied on (14) company, view point of managers. There are effect by information technology, in decision marketing process, the best strategy y is cost leader.

The study recommended by: reduce the cost developed the performance adaptation with it developing focus on research.

Nsoor Abd Al_Hakeem (2009) "competitive performance in Jordanian medicine company" Syria

The study aimed to explore the importance of medicine sector in national economy, knowledge competitive factors, competition, secure medicine product ion of Jordanians, competition ability of competition, scales, of production, rate of reinvestment, supply and demand, roles of government.

The study recommended by increase the ability of competitive advantage, rate of the demand, focus on innovations, develop the performance, support the medicines' industry, develop the new strategies as increasing production. 
Amen Jabber (2003) "effect consolidation on Jordanian medicine industry " Jordan.

The study aimed to: the effect of consolidation on medicine competition, market share of medicine in national economy, analyze the competition factors the study explore; the effect of investment by working capital, amount of production competition abilities.

The study recommended by: the Jordanian medicine industry is very good consideration suitable for ordain companies, focus on competition abilities, increase the technology expansures, increase the market share more attraction, more satisfaction.

Rahala Nassem (1997) "Jordanian medicine industry" Jordan.

The study aimed to explore the role of medicine industry in Jordan, effects of patients, equities, sales, demand of medicine, decrease the market share of medicine industry between 19751995, decrease labor opportunities, high prices, limitations of demand.

The study recommended by: develop the styles of production, decrease the prices, increase employee usages, focus on demand limitations, motivate the external demand, increase the market share in GDP.

\section{Jordanian Medicine Sector}

This sector has been deal with external sector in many countries (60) and cover most needs in local market, register more than (80) patent, it has (106) firm in Jordan, (18) firm outside Jordan, depend on low cost compare with external countries, its export was (600-620) million J.D yearly for 2012-2014. This sector respect the laws, regulation in Jordanian economy, share about (5\%) of national economy (Global industrial committee report 2014).

The Jordanian medicine production is become a competitor in regional markets because have a good management, senseve belongingness, social responsibility, ethics, applied international criteria in production (European report 2012). This sector begin in 1962, but today has (106) firm in medicine their related, it consider the pioneer sector. In Arab world and share in industrial sector by (8\%) $2004-2010$, but (75 \%) from production is oriented for export.

This sector has opportunities to expansion depend on regional countries which extended the insurances converge part, increase the degree of medicine culture, increase the demand, and has about (8000) employees most of them professionals' or has a high graduated and efficiency. It try to achieve competition advantages (moalla 2014).

\section{The Medical Production}

1. Medicine

2. Consumption medical

3. Biotechnology

4. Pharmaceutical medicine

5. Veterinary drug master

6. Medical supplies

7. Reagents, solutions

\section{The Marketing Strategies}

In whole the strategy is plan, tool, way, manner of application to saturate customer needs, wants, preferences and achieving the firms goals to exist, continuous, growth (kilter 2006). 


\section{Pricing Strategies}

Its the operation which determine the prices depend on plan, tool, way, manner applicated to achieves the goals of firms by satisfying the customer needs, wants and save the firms sustainable. How we will achieve the medicine acceptance, we ought to motivate the customer in target market and focus on competition abilities (moalla 2007). That we know the prices is what paid instead of acquisition any thing with main request to achieve revenues.

\section{Skimming Strategies}

\section{STRATEGIES KINDS}

They are two strategy in this kind it depend on launching medicine production in high prices to achieve a big part of revenues (skim the cream). It consist of two shapes rapid skimming, low skimming, the suitable situation of applicative it if the degree of customer sensitive for prices is low and high prices is mean high quality thus strategy depend on elements (prices, promotion).

\section{Penetration Strategy}

There are two kind of strategy in this type, it depend on launching new medicine production in low prices to achieve part of revenue in long term and accept the production slowly (skim the cream finally). It consist of two shapes, rapid penetration, low penetration, the suitable situation of applicative it. If the market is huge, customer sensitive of prices is high, the time is wide, the strategy depend on two element (price, promotion).

\section{Expected Value Strategy}

There are many level for customer expectations (perceptions) if the perceived value equal his expectation or above that or below that, in this strategy the prices care with value and what mean for the benefits of binging the production in low way, and what the opportunities to achieve benefits continuously. Medicine production (new, necessary, valuable....) what the degree of prices sensitive by customers, what is the values of quality. The marketer should care with the customers and understanding them view points and there perceptions, expectations, need, wants, preferences, its necessary to planning the prices as they want and they understanding to achieving satisfaction gradually and completely.

\section{The Customer Satisfaction}

Its very necessary to understanding the customer needs because the customer have a great purchasing power, benefits depend on customer satisfactions, the firm achieve loyalty for its production. Keeping the customers, attractive new customers, their are many principles to consider. It when we planning for achieving the customer satisfaction as: value, worth, quality, changes of customer behavior, benefits, revenues, growth, goals. We should remember the cost of new customer is more than constant customer, the level of competition market, target market. (Zyadat, Awmmra 2012).

\section{Pricing Methods}

The pricing competition require changing the pricing policies depend on statuee of market, competition customers product (Michael 2002).
A. Market oriented pricing
B. Pricing based cost
C. Latent pricing
D. Pricing based competition
E. Multiple Stage Pricing
F. Pricing Based on Production 


\section{Effecting Medicine Pricing Factors}

A: External Factor: strategies lows and regulation, customer, competitors, intermediars B: Local Factors: competition, government support goals, cost, marketing mix, management, policies.

\section{The Study Population and Sample}

The study population consist of all the managers in Jordanian medicine sector by (106) firm the researcher selected a survey a sample of study population by view point of manager who response (81) manager.

\section{Model of Study}

The study aimed to identify the level of customer satisfaction in Jordan medicine sector about pricing strategies, to achieve this a model was designed for the study that is described the relationship between independent variables represented in the (dimension of pricing strategies) and the dependent variables represented in (customer satisfaction).

\section{Independent factor}

1. Skimming strategy
A. (rapid)
B. (low)
2. Penetration strategy
A. (rapid)
B. (low)
3. Expected
value strategy

\section{Dependent factor}

\section{Study Hypothesis}

The study hypothesis have been formulated based on the problem and variables of the study:

1. There is no statistically significant relationship at $(\mathrm{a}<=0.05)$ between medicine pricing strategy its dimensions (Rapid skimming, low skimming, rapid, penetration, low penetration, expected value) and the customer satisfaction in Jordan.

2. There is no statistically significant relationship at $(a<=0.05)$ between (Rapid skimming strategy) in medicine sector and customer satisfaction in Jordan.

3. There is no statistically significant relationship at $(a<=0.05)$ between (low skimming strategy) in medicine sector and customer satisfaction in Jordan.

4. There is no statistically significant relationship at $(\mathrm{a}<=0.05)$ between (rapid penetration strategy) in medicine sector and customer satisfaction in Jordan.

5. There is no statistically significant relationship at $(\mathrm{a}<=0.05)$ between (low penetration strategy) in medicine sector and customer satisfaction in Jordan.

6. There is no statistically significant relationship at $(a<=0.05)$ between (expected value strategy) in medicine sector and customer satisfaction in Jordan. 


\section{The Study Tool}

To answer the questions of sudy and test hypotheses the researcher prepared questionnaire for this purpose on market research, the first part of the questionnaire is contained independent variables (dimensions of strategy: skimming, penetration, expected value) but the second part deal with dependent variable (customer satisfaction).

\section{Statistical Treatment}

After the researcher had finish from collecting data on variable of study, some statistical indicator and method in the statistical package for social science (SPSS) used:
A. Reliability of scales
B. Descriptive Statistics
C. Correlation
D. Co linearity
E. $\mathrm{R}, \mathrm{R}^{2}$
F. ANOVAs
G. Coefficients

\section{RESULTS OF TESTING THE STUDY HYPOTHESES \\ The detail explanation of the results of testing:}

The suitable strategy for pricing the medicine production as possible as the customer orientations. The test validity of first hypotheses (strategies) the simple correlation coefficient (spearman) was used in order to measure the relationship between pricing strategies and customer satisfaction and each of dimensions as table(3). The results presented indicated the presence relations that are statistical y significant, what supports this is the (P-value) which equals $(0.000)$ for all dimensions which than the level of significance $(a=0.05)$

In order to measure the relationship between skimming strategy and customer satisfaction as table (4), the results are statistically significance which equals (0.000) for dimensions (Rapid, Low). Which more than level of significance $(a=0.05)$ because the medicine is necessity, healthy and the government, firm support the cost mostly and the although dimensions of strategy in penetration, expected).

In order to measure the reliability of scale as which achieve a good degree of validity (0.84) as table (1) and there are internal consistency between variable as table (4) mentioned depend on (VIF) indictor. But the standard deviation for customer satisfaction becomes middle of table (2).

In the same time the correlation lay between (0.05-0.01) which mean significances as table (3), and calculated (F) values becomes $(426,775)$ bigger the (F) spread sheet which means significances as table (6), finally the variables of study becomes effectively as (Beta) coefficient indicates in table (7).

\section{The Results of Study explain the following}

1. Rapid skimming strategy depend on the importance of the medicine at its necessity.

2. The penetration strategy is the suitable way for enter level of the medicine need.

3. Expected value strategy depend on customers perceptions and target markets.

4. The medicine prices now is very high.

5. Lock of government support.

6. Leak of the for demand market share regionally and globally. 
7. Low of customer satisfaction about many medicines prices.

8. The cost of the medicine sector developing very high. Depend on technology changes.

The study recommended the following:

\section{RECOMMENDATIONS}

1. Achieving the customer satisfaction, increasing loyalty.

2. The Jordan medicine sector ought to focus on a suitable pricing strategy.

3. Decrease the cost of productions about importance of health medicine.

4. Develop the customer's perception about the importance of health medicine.

5. Increasing the level of government support.

6. Develop the medicine sector, quality, technology, health, care, changes.

7. Rehabilitating, training, raising the efficiency of employees.

8. Reinforcement of export and competition abilities.

9. Increase the Jordan medicine sector share.

10. Focus on comprehensive health care in Jordan.

\section{References}

Although a'a said (2014) "the effect of strategic performance in Jordan medicine firms" meddle east university, Jordan, unpublished research.

Zayadant, Awamra (2012) "marketing strategies". Jordan, Amman, alhamed stores, 2th edition.

Moala naji (2012) "marketing management". Jordan, Amman, international store,

Moala naji (2012) "marketing management". Sales management. "Jordan Amman alhamed store, Allseed Mustafa (2012) "Arab medicine industry" Egypt, Cairo.

Obiedat Mohammed (2010) "sales management personal, selling" Jordan, Amman, weal stores.

Al nsoor abed (2009) "competitive performance in Jordan medicine firms" Syria, unpublished.

Paris l. and belta (2007) "consumer bearers; concept and application" USA, NewYork.

Michal P (2005) "competitive strategy: techniques, analyzing industries, and competitors" USA, NewYork.

Kilter, Philip (2006) "marketing management" $12^{\text {th }}$ ed, USA, NewYork, prentice hill.

Jabber amen (2003) "the of consolidations in Jordan medicine firm" Jordan, Amman unpublished research.

Rahall naseem (1997) "Jordan medicine industry" Jordan, Amman un publisher research, Jordan industry chamber (2012) report.

Europeans report (2012) international industry committee (2012) report. 